\title{
Prevalence of Salmonella Typhi Among Patients in Abia State University Teaching Hospital Aba Abia State, Nigeria
}

\author{
Ezejindu C. $\mathbf{N}$
}

Department of Public Health, Faculty of Health Sciences (Clinical Medicine) College of Medical and Health Sciences ,Abia State University, Uturu,Abia State, Nigeria

ezejinducosmas@gmail.com

Abstract: This study was carried out to evaluate the prevalence of typhoid fever between genders among patients in Abia State Teaching Hospital. Typhoid fever which is caused by Salmonella typhi an endemic disease in the tropic and sub-tropic regions and has become a major public health problem in developing countries of the world with an estimated annual incidence of 560 per 100,000. The annual incidence of typhoid is estimated to be about 18 million cases worldwide. It is mostly seen in tropical countries including Nigeria where they lead to serious morbidities and mortalities. Blood samples were collected from 600 healthy people; $36 \mathrm{j} 0$ $(60 \%)$ females and $240(40 \%)$ males. The samples were examined for the presence and levels of Salmonella typhi antibodies using Widal agglutination technique. The standard Salmonella 'O' and 'H' suspension (ANTEC diagnostic products) were used as antigens. Out Of the 600 sera tested, agglutinins to Salmonella typhi were most prevalent in female subjects accounting for[300(88.2\%)] of the ' $\mathrm{H}$ ' antigens and [230(96.1\%)] of ' $\mathrm{O}$ ' antigens at the various dilutions while in the male subjects, [250(92.4\%)] accounts for the ' $O$ ' and [220(84.6\%)] for the ' $\mathrm{H}$ ' antigens.The results of this study showed that more males had Salmonella agglutinin titres for $S$. typhi 0 [250(96.1\%)] and S. typhi $H$ [220(84.6\%)]. More so, 100 (38.5\%) males had Salmonella agglutinin titres for S.paratyphiA-0, 90 (34.6\%) for S. paratyphi B-0, 85 (32.7\%) for S. paratyphi C-0, 87 (32.6\%) for S. paratyphi A-H, 89 (34.2\%) for S. paratyphi B-H, and 60 (23.1\%) for S. paratyphi C-H. It also showed that more females had Salmonella agglutin in titres for S. typhi H [300 (88.2\%)] followed by S. typhi O [223(65.6\%)], $S$. paratyphi B-H [116 (34.1\%)], S. paratyphi B-0 [128(37.6\%)], S. paratyphi B-0 [120(35.3\%)], S. paratyphi C-0 [122(35.9\%)], S. paratyphi A-H [118 (34.7\%)], and S. paratyphi C-H [113 (33.2\%)]. The findings of this study establish Salmonella typhi titres that are not diagnostically significant but normal in the study population and the titre that could be used as presumptively diagnostic of typhoid fever.

Keywords: Agglutinin, Salmonella tyhi, Salmonella paratyhi, Widal test, typhoid fever, Nigeria

\section{INTRODUCTION}

Typhoid fever, also known as enteric fever, is a potentially fatal multisystemic illness caused primarily by Salmonella enterica, subspecies entericaserovartyphi and, to a lesser extent, related serovarsparatyphi A, B, and C (Crumpet al., 2010).

Typhoid fever, also known simply as typhoid, is a bacterial infection due to Salmonella typhi that causes symptoms which may vary from mild to severe and usually begin six to thirty days after exposure. Often there is a gradual onset of a high fever over several days. Weakness, abdominal pain, constipation, and headaches also commonly occur. Diarrhoea is uncommon and vomiting is not usually severe(Crumpet al., 2010).

It is an endemic disease in the tropic and sub-tropic and has become a major public health problem in developing countries of the world with an estimated annual incidence of 560 per 100,000 (Ibekweet al., 2008). The annual incidence of typhoid is estimated to be about 17 million cases worldwide (WHO, 2008). It is often encountered 
Prevalence of Salmonella Typhi Among Patients in Abia State University Teaching Hospital Aba, Abia State, Nigeria

in tropical countries including Nigeria where they constitute serious sources of morbidities and mortalities (Anna, (2014). Typhoid and paratyphoid fevers are transmitted through faecal oral.Typhoid fever can be gotten through Contaminated water (WHO, 2008). Typhoid and paratyphoid fevers are caused by the bacteria Salmonella typhi and Salmonella paratyphi, respectively.Once the bacteria enter the person's body they multiply and spread from the intestines, into the bloodstream. Even after recovery from typhoid or paratyphoid, a small number of individuals (called carriers) continue to carry the bacteria. These people can be a source of infection for others (WHO, 2008). The transmission of typhoid and paratyphoid in less-industrialized countries may be due to contaminated food or water. Typhoid fever is rare in industrialized countries. However, it remains a serious health threat in the developing world, especially for children. In some countries, shellfish taken from sewage-contaminated beds is an important route of infection. Where water quality is high, and chlorinated water piped into the house is widely available, Transmission is more likely to occur via food contaminated by carriers handling food (WHO, 2008).Based on the immunology of Salmonella infection, serological diagnostic tests relying on Salmonella antigens as a tentative evidence of salmonellosis have been developed, notably, the Widal agglutination test. Widal test appears to be the only laboratory means employed in the diagnosis of typhoid fever among suspected patients (Widal test appears to be the only laboratory means employed in the diagnosis of typhoid fever among suspected patients (Yap et al., 2014). Salmonella typhi is Gram-negative bacteria, which are motile, though non-flagellate variantsoccur, Capsules are not formed.). Salmonella are divided into distinct serologic groups (A through $\mathrm{E}$ ) on the basis of their somatic $\mathrm{O}$ antigens. While all group D organisms, such as $S$. typhi possess 0 antigen 9 , about 60 of the 78 groups D serotypes including $S$. typhi also have 0 antigen 12 . Thus, infection by any of the group D serotypes can produce antibodies that can react with the $\mathrm{O}$ antigen used in the Widal reaction (Olopoeniaet al., 2000).

\section{Materials And Methods}

\section{Study Area}

This study was conducted among patients attending Abia State University Teaching Hospital Aba, Abia State, Nigeria.

\section{Sample Collection}

A total of 600 blood samples were collected from 600 patients ( 360 females and 240 males) attending the Abia State Teaching Hospital Aba. The samples were collected in sterile containers and were sent to the laboratory for processing and to be analysed. The samples were obtained by informed consent of the patients used for this study and the permission to that effect was obtained from the ethical committee. Two millilitres of the blood samples were centrifuged at a high speed for $5 \mathrm{~min}$ in order to separate the serum from the blood cells.

\section{Widal Agglutination Test}

ANTEC febrile antigen kit was used for the Widal test. The rapid slide screening test was first carried out, followed by the tube agglutination test according to the manufacturer's specifications. The ANTEC febrile antigens are suitable for both the rapid slide and tube agglutination tests against human sera for the detection of these agglutinins. The stained antigen suspensions are killed bacteria, stained to enhance the reading of agglutination tests. The blue stained antigens are specific to the somatic ' 0 ' antigens whilst the red stained antigens are specific to the flagella ' $\mathrm{H}$ ' antigens. Using a pipette, $0.08,0.04,0.02,0.01$ and $0.005 \mathrm{ml}$ of undiluted serum was dispensed onto a row of $3 \mathrm{~cm}$ diameter circles. The reagent bottle was shaken rigorously and a drop of the undiluted antigen suspension was added to each serum aliquot. This was thoroughly mixed with the aid of a stirring stick and the slide was gently rotated. The reactions were observed after a minute. 
Prevalence of Salmonella Typhi Among Patients in Abia State University Teaching Hospital Aba, Abia State, Nigeria

\section{RESULTS}

Table 1. Incidence of Widal Positive Sera (Salmonella Agglutinin titres) in Relation to Sexes of the Subjects in Abia State Teaching Hospital

\begin{tabular}{|c|c|c|c|}
\hline SEX & NO OF SERA TESTED & NO OF WIDAL POSITIVE \% & NO OF WIDAL NEGATIVE \% \\
\hline Female & $340(56.7)$ & $230(67.6)$ & $110(32.3)$ \\
\hline Male & $260(43.3)$ & $250(96.1)$ & $10(3.8)$ \\
\hline Total & $\mathbf{6 0 0 ( 1 0 0 . 0 )}$ & $\mathbf{4 8 0 ( 8 0 . 0 )}$ & $\mathbf{1 2 0 ( 2 0 . 0 )}$ \\
\hline
\end{tabular}

Table 2. Distribution of Salmonella Agglutinin in Titres in 260 Male Subjects in Abia State Teaching Hospital

\begin{tabular}{|c|c|c|c|}
\hline SALMONELLA & NO OF SERATESTED & NO OF WIDAL POSITIVE \% & NO OF WIDAL NEGATIVE \% \\
\hline S. paratyphiA-O & 260 & $100(38.5)$ & $160(61.5)$ \\
\hline S. paratyphi B-O & 260 & $90(34.6)$ & $170(65.4)$ \\
\hline S. paratyphiC-0 & 260 & $85(32.7)$ & $175(67.3)$ \\
\hline S. typhiO & 260 & $240(92.5)$ & $20(77)$ \\
\hline S. paratyphiA-H & 260 & $87(32.6)$ & $173(65.5)$ \\
\hline S. paratyphiB-H & 260 & $89(34.2)$ & $171(65.8)$ \\
\hline S. paratyphiC-H & 260 & $60(23.1)$ & $20(76.9)$ \\
\hline S. typhiH & 260 & $220(84.6)$ & $40(15.4)$ \\
\hline
\end{tabular}

Table 3. Number and Percentage of Sera with End Titres in 260 Male Subjects in Abia State Teaching Hospital

\begin{tabular}{|c|c|c|c|c|c|}
\hline SALMONELLA & NO OF WIDAL POSITIVE \% & $<\mathbf{8 0}$ & $\mathbf{8 0}$ & $\mathbf{1 6 0}$ & $\mathbf{3 2 0}$ \\
\hline S. paratyphiA-0 & $100(38.5)$ & $13(13.0)$ & $52(52.0)$ & $29(29.0)$ & $04(04.0)$ \\
\hline S. paratyphiB-0 & $90(34.6)$ & $14(14.5)$ & $40(44.4)$ & $24(26.6)$ & $00(00.0)$ \\
\hline S. paratyphi C-O & $85(32.7)$ & $20(23.5)$ & $32(37.6)$ & $21(24.7)$ & $02(02.4)$ \\
\hline S. typhiO & $240(92.3)$ & $04(0 \mathrm{I} .1)$ & $46(19.2)$ & $150(62.5)$ & $19(07.9)$ \\
\hline S. paratyphiA-H & $87(32.6)$ & $08(0.92)$ & $50(57.5)$ & $06(6.9)$ & $00(00.0)$ \\
\hline S. paratyphiB-H & $89(34.2)$ & $24(27.0)$ & $62(69.7)$ & $8(8.9)$ & $00(00.0)$ \\
\hline S.paratyphiC-H & $30(11.5)$ & $16(53.3)$ & $18(60.0)$ & $07(23.3)$ & $00(00.0)$ \\
\hline S. typhiH & $250(96.2)$ & $20(8.0)$ & $160(64.0)$ & $40(16.0)$ & $01(00.4)$ \\
\hline
\end{tabular}


Prevalence of Salmonella Typhi Among Patients in Abia State University Teaching Hospital Aba, Abia State, Nigeria

Table 4. Distribution of Salmonella Agglutinin in Titres in 340 Female Subjects in Abia State Teaching Hospital

\begin{tabular}{|c|c|c|c|}
\hline SALMONELLA & NO OF SERATESTED & NO OF WIDAL POSITIVE \% & NO OF WIDAL NEGATIVE \% \\
\hline S.paratyphiA-O & 340 & $120(35.3)$ & $220(64.7)$ \\
\hline S.paratyphiB-O & 340 & $128(37.6)$ & $212(62.3)$ \\
\hline S.paratyphiC-O & 340 & $122(35.9)$ & $218(64.1)$ \\
\hline S.typhiO & 340 & $223(65.6)$ & $117(344)$ \\
\hline S.paratyphiA-H & 340 & $118(347)$ & $222(65.2)$ \\
\hline S.paratyphi B-H & 340 & $116(34.1)$ & $224(66.0)$ \\
S. paratyphi C-H & 340 & $113(33.2)$ & $227(66.8)$ \\
S.typhi H & 340 & $300(88.2)$ & $40(11.8)$ \\
\hline
\end{tabular}

Table 5. Number and Percentage of Sera with End Titres in 340 Females inAbia State Teaching Hospital

\begin{tabular}{|c|c|c|c|c|c|}
\hline SALMONELLA & NO OF WIDAL POSITIVE \% & $<\mathbf{8 0}$ & $\mathbf{8 0}$ & $\mathbf{1 6 0}$ & $\mathbf{3 2 0}$ \\
\hline S. paratyphi A-O & $120(35.3)$ & $14(11.7)$ & $50(41.7)$ & $58(48.3)$ & $12(10.0)$ \\
\hline S. paratyphi B-0 & $128(37.6)$ & $12(9.4)$ & $62(48.4)$ & $60(46.7)$ & $03(02.3)$ \\
\hline S. paratyphi C-0 & $122(35.9)$ & $20(16.4)$ & $56(46.0)$ & $37(30.3)$ & $03(02.3)$ \\
\hline S. typhi O & $223(65.6)$ & $02(01.6)$ & $69(31.0)$ & $223(100.0)$ & $30(13.5)$ \\
\hline S. paratyphi A-H & $118(34.7)$ & $10(8.5)$ & $92(78.0)$ & $10(85)$ & $00(00.0)$ \\
\hline S. paratyphi B-H & $116(34.1)$ & $22(19.0)$ & $96(82.8)$ & $16(13.8)$ & $00(00.0)$ \\
\hline S. paratyphi C-H & $113(33.2)$ & $14(12.4)$ & $66(58.4)$ & $16(14.2)$ & $00(00.0)$ \\
\hline S. typhi H & $300(88.2)$ & $06(01.2)$ & $280(93.3)$ & $120(40.0)$ & $02(00.6)$ \\
\hline
\end{tabular}

The distribution of Salmonella agglutinin titres obtained from 600 (100\%) subjects' sera from Abia State University Teaching Hospital; 340 (56.7\%) females and 260 (43.3\%) males is shown in Table 1-5. Table 1 shows the incidence of Widal positive sera (Salmonella agglutinin titres) according to sexes of the subjects in Abia State University Teaching hospital. It showed that $480(80.0 \%)$ of the samples analysed for Salmonella agglutinin titres were Widal positive while 120 (20\%) were Widal negative as shown in Table 1. It also showed that $96.1 \%(n=250)$ of the sera from males were Widal positive and $67.6 \%(n=230)$ of the sera from females were also Widal positive (Table 1)

Table 2 shows the distribution of Salmonella agglutinin titres in 260 male subjects inAbia State University Teaching Hospital. The result showed that more males had Salmonella agglutinin titres for S. typhi 0 [250(96.1\%)] and S. typhi H [220(84.6\%)]. More so, 100 (38.5\%) males had Salmonella agglutinin titres for S. paratyphi B-O, 90 (34.6\%) for S. paratyphi C-0, 85 (29.5\%) for S. paratyphi A-H, 87 (32.6\%) for S.paratyphi B-H, $89(34.2 \%)$ for S. paratyphi C-H, and $60(23.1 \%)$ for S. paratyphi C-H as shown in Table 2. 
Prevalence of Salmonella Typhi Among Patients in Abia State University Teaching Hospital Aba, Abia State, Nigeria

Table 3 shows the frequency and percentage of sera with end-titres in 260 male subjects inAbia State University Teaching Hospital. It was observed that with exception of S. paratyphi B-O and S. paratyphi A-H, S. paratyphi B-H, and S. paratyphi C-H, all other agglutinins tested were present in the sera of males up to the titre of 320 and at frequencies/percentages ranging from $1(0.3 \%)-250$ (96.1\%). However, the frequency of Salmonella agglutinins titre of $<1: 80$ ranged from $4(1.1 \%)$ to $24(27.0 \%) ; 1: 80$ from $46(19.2 \%)$ to $160(64.0 \%) ; 1: 160$ from $6(6.9 \%)$ to $150(62.5 \%)$ and $1(0.4 \%)$ to $19(7.9 \%)$ for $1: 320$. The results showed that titres of 1:80 and 1:160 occurred in a significant proportion of the samples as shown in Table 3.

Table 4 shows the distribution of Salmonella agglutinin titres in 340 female subjects inAbia State University Teaching Hospital. The result also showed that more females had Salmonella agglutinin titres for S. typhi H [300 (88.2\%)] followed by S. typhi 0

[223(65.6\%)], S. paratyphi B-H [116 (34.1\%)], S. paratyphi B-O [128(37.6\%)], S. paratyphi B-H [116(34.1\%)], S. paratyphi C-O [122(35.9\%)], S. paratyphi A-H [118 (34.7\%)], and S. paratyphi C-H [113 (33.2\%)] as shown in Table 4.

Table 5 shows the frequency and percentage of sera with end-titres in 340 female subjects in Abia State University Teaching Hospital. It was observed that with exception of S. paratyphi A-H, S. paratyphi B-H and S. paratyphi $\mathrm{C}-\mathrm{H}$, all other agglutinins tested were present in the sera of females up to the titre of 320 and at frequencies/percentages ranging from 4(0.9\%)223(100.0\%). However, the frequency of Salmonella agglutinins of $<1: 80$ titre ranged from $5(1.6 \%)$ to $20(16.4 \%) ; 1: 80$ from $50(41.7 \%)$ to $280(93.3 \%) ; 1: 160$ from $16(13.8 \%)$ to $223(100.0 \%)$ and $2(0.6 \%)$ to $42(13.0 \%)$ for $1: 320$. The results showed that titres of 1:80 and 1:160 occurred in a significant proportion of the samples as shown in Table 5.

\section{DISCUSSION}

In this study, $480(80.0 \%)$ of the $600(100.0 \%)$ blood samples gave positive Widal reaction. This indicates a high prevalence of typhoid fever in the sampled population. However, some of the subjects may not be having the active disease. This is in agreement with the observations of Adelekeet al. (2006) in a similar study on Widal reaction as being more relevance in diagnosing post-infection complications when S.typhi may not be isolated.

Here, the Widal test was employed which involves the use of bacterial suspensions of S. typhi and S. paratyphi ' $A$ ' and 'B', treated to retain only the ' $O$ ' and ' $H$ ' antigens. These antigens are employed to detect corresponding antibodies in the serum of a patient suspected of having typhoid fever. While bacteriological culture remains the gold standard for definitive diagnosis of typhoid fever, lack of its immediate availability during the acute febrile illness may limit its use. In an acute febrile illness in an endemic typhoid region where the clinical picture is ambiguous, a rapid, accurate, specific and sensitive test should be used to differentiate typhoidal from nontyphoidal febrile illnesses (Olopoeniaet al., 2000).

In endemic typhoid regions, a single testing of a serum specimen for Widal agglutinin cannot provide a reliable diagnosis due to: repeated exposure to small inoculum of S.typhi or to other Salmonella spp. that contain type 9 or 12 antigens, previous typhoid fever immunization and other infectious agents such as malaria (Olopoeniaet al., 2000).

In this study, more sera from males were more Widal positive than sera from females. This may be as a result of different eating habits and level of personal hygiene. This is also in agreement with the findings of Adelekeet al. (2006).

In 260(43.3\%) males, the titre of Salmonella 'O' were higher than those of the ' $\mathrm{H}$ ' while in $340(56.7 \%)$ females, Salmonella ' $\mathrm{H}$ ' titres were higher than those of ' $\mathrm{O}$ '. This differs from what was reported in a similar study by Ibekweet al. (2008) where 82 apparently normal males had higher titre of Salmonella 'H' and 118 apparently 
Prevalence of Salmonella Typhi Among Patients in Abia State University Teaching Hospital Aba, Abia State, Nigeria

normal females had higher Salmonella 'O' titres (Ibekweet al., 2008). Agglutinins to S. typhi were the most prevalent among the sera tested at various dilutions in both males and females.

Agglutinins to $S$. typhi were the most prevalent among the sera tested at various dilutions in both males and females. Three hundred and fifty-one [250(96.1\%)] had higher titre for S. typhi '0'and 220 (84.6\%) for S. typhi ' $\mathrm{H}$ ' than in the females with 223 (65.6\%) for the S. typhi ' $\mathrm{O}$ ' and $300(88.2 \%)$ for the S. typhi ' $\mathrm{H}$ '. Agglutinin level for the typhoid and paratyphoid group tested in this study were evidently very frequently found in the sera of the subjects. The levels of agglutinin of Salmonella paratyphi C-H [30(11.5\%)] and Salmonella typhi C-0 [85(32.7\%)] in the males were however, low. Agglutinin titres of 80 were observed in only 46(19.2\%) and $32(37.6 \%)$ for Salmonella typhi $\mathrm{O}$ and Salmonella paratyphi C-O respectively. In the females, the low significant agglutinin titres for Salmonella typhi 0 and Salmonella paratyphi A-O were observed in $69(31.0 \%)$ and 50 (41.7\%) of the sera respectively. This is concurrent with the findings of Okonkoet al., (2010).

Typhoid and paratyphoid fevers are common in the developing countries, as a result of unsafe drinking-water, inadequate sewage disposal, level of awareness of food hygiene practice, flooding. Public health interventions to prevent typhoid and paratyphoid which include: Health education on personal and environmental hygiene, especially on the principles of hand-washing after toilet use and before food preparation; provision of a safe water supply; Proper sanitation systems; Excluding disease carriers from food handling. More so, the use of antibiotics as a control measure. A vaccine is available, although it is not routinely recommended except for those who will have prolonged exposure to potentially contaminated food and water in high-risk areas. The vaccine does not provide full protection from infection (WHO, 2008).

\section{CONCLUSION}

In conclusion, the prevalence of typhoid fever and the increasing Multi-Drug Resistance (MDR) of its causative agent seriously constitute a serious harm in developing countries. The effect on health status would affect productivity, intellectual development and other aspects of life (Adelekeet al., 2006). Hence, there is an urgent need, for measures to curb out the spread of the disease. However, Widal agglutination titres higher than 1:80 should be an index of presumptive diagnosis of typhoid fever (Ibekweet al., 2008).There should be proper orientation to the populace on the importance of intake of safe water, hand washing after toilet and before eaten, and food hygiene practice. Therefore, efforts must be made however, to confirm the diagnosis by paired sera investigation more than in presently the case. The world Health Organisation (WHO) should as well produce vaccine that will produce full protection from this infection.

\section{REFERENCE}

1. Adeleke, O.E., T.J. Adepoju and D.A. Ojo, 2006.Prevalence of typhoid fever and antibiotic Susceptibility pattern of its causative agent Salmonella typhi.Nigerian J. Microbio., 20(3): 1191-1197.

2. Anna E. Newton (2014). “3 Infectious Diseases Related To Travel”. CDC health information for International travel 2014: the yellow book. ISBN 9780199948499

3. Crump, JA; Mintz, ED (15 January 2010). “Global trends in typhoid and paratyphoid Fever."ClinicalInfectious Diseases.50 (2): 241-6.

4. Ibekwe, A.C., I.O. Okonko, A.U. Onunkwo, E. Donbraye, E.T. Babalola and B.A. Onoja, 2008. BaselineSalmonella agglutinin titres in apparently healthy freshmen in Awka, South Eastern, Nigeria. Sci. Res.Essay, 3(9): 225-230. 
Prevalence of Salmonella Typhi Among Patients in Abia State University Teaching Hospital Aba, Abia State, Nigeria

5. OkonkoI.O., F.A. Soleye, O.D. Eyarefe, T.A. Amusan, M.J. Abubakar, A.O. Adeyi, M.O. OjezeleAndA. Fadeyi(2010)"Prevalence of Salmonella typhi among Patients in Abeokuta, South-Western Nigeria. British Journal of Pharmacology and Toxicology 1(1): 6-14.

6. Olopoenia, L.A., A.I. King and F.A. Santanga, 2000. Classic methods revisited. Widal agglutination test100 years later: still plagued by controversy. Postgraduate Med. J., 76(892): 80-84.

7. Yap, Kien-Pong; etal. (2014). “Comparative genomics of closely related Salmonella entericaSerovarTyphi strainsrevealsgenomedynamicsandtheacquisition of novelpathogenicelements."BMCGenomics.15 (1): 1007.

8. World Health Organization (WHO), 2008.Prepared for World Water Day 2001. Reviewed by staff and experts from the cluster on Communicable Diseases (CDS) and the Water, Sanitation and Health unit (WSH), World Health Organization (WHO), 2008.

Citation: Ezejindu C. N. "Prevalence of Salmonella Typhi Among Patients in Abia State University Teaching Hospital Aba, Abia State, Nigeria". American Research Journal of Endocrinology; 1(1): 18-24.

Copyright (c) Ezejindu C. N, This is an open access article distributed under the Creative Commons Attribution License, which permits unrestricted use, distribution, and reproduction in any medium, provided the original work is properly cited. 